\title{
Malignant Gastric Neoplasm
}

National Cancer Institute

\section{Source}

National Cancer Institute. Malignant Gastric Neoplasm. NCI Thesaurus. Code C9331.

A primary or metastatic malignant neoplasm involving the stomach. 